\title{
Testicular cancer mortality in England and Wales 1971-80: variations by occupation
}

\author{
M E MCDOWALL ${ }^{1}$ AND R BALARAJAN ${ }^{2}$ \\ From the Medical Statistics Division, ${ }^{1}$ Office of Population Censuses and Surveys, and Medical Department, ${ }^{2}$ \\ South West Thames RHA and Department of Clinical Epidemiology, St Georges Hospital Medical School, \\ London SW17
}

SUMMARY The occupations of all males aged 15 and over dying of cancer of the testis in England and Wales from 1971 to 1980 (2434 cases) have been examined in a case control study. Significant excess mortality was found in farmers (although not farm workers), food manufacture and preparation workers, and draughtsmen, although the results show little evidence of a major role for occupation in the aetiology of this cancer. The results may, however, aid the search for those factors in modern life that may have contributed to the sharp rise in incidence of this cancer in recent years.

The incidence of testicular cancer in young men has been rising in England and Wales over the last 50 years. ${ }^{1}$ Other developed countries, notably Denmark, Japan, and the USA, have shown similar increases. $^{2-5}$ The reasons for this increase, and the aetiology of this cancer, remain largely obscure, but there is no evidence to suggest that diagnostic changes could have contributed much to the increased mortality. ${ }^{6}$ Certain medical conditions, in particular cryptorchidism and atrophic testes, have been shown to be associated with increased risk of this cancer, ${ }^{7-9}$ but it is not clear that changes in these factors could fully account for the rising incidence. ${ }^{10}$ Trauma $^{11}$ and excessive heat ${ }^{12}$ have also been associated with testicular cancer. Case-control analyses $^{13}$ and studies of routine incidence ${ }^{14}$ and mortality ${ }^{1}$ data have shown a social class gradient with higher risks for professional workers. Increased risk has also been suggested for sawmill and other mill workers, ${ }^{15}$ agricultural workers ${ }^{916}$ and for employment in the oil and natural gas extraction industries. ${ }^{9}$ However, the characteristics of testicular cancer incidence suggest that occupation as such is unlikely to have more than a minor role in its aetiology. ${ }^{1}$ A study of mortality by occupation may nevertheless assist consideration of those features of modern life that may be associated with increased risk.

\section{Materials and methods}

A death certificate case control study of mortality from testicular cancer in England and Wales was conducted to identify any occupations apparently at raised risk. Cases were all deaths to males aged 15 and over from 1971 to 1980 in England and Wales where the underlying cause of death was recorded as cancer of the testis (ICD 186)-2434 deaths. There were no known changes in diagnostic or certification practice during the period 1971 to 1980 that could have influenced the outcome of the study. Deaths from 1971 to 1978 were coded according to the 8th Revision of the International Classification of Diseases (ICD), and deaths in 1979 and 1980 according to the 9th Revision. However, the classification change did not affect the coding of cancer of the testis. One control for each case was randomly chosen from male deaths aged 15 and over from all other cancers, matching for year of death and age to within five years of the case. Mortality rates from cancer of the testis peak in the age group $25-34,{ }^{1}$ and at these ages there is a particularly disproportionate mortality from accidents. ${ }^{17}$ Several occupations are associated with high accident mortality so the inclusion of accidental deaths in the controls would have produced a bias in the results for such occupations. In addition, several lesser causes of death (eg, diabetes, epilepsy, congenital anomalies) are also proportionately more common at younger ages, ${ }^{17}$ and sufferers from such conditions may have selected themselves into specific, perhaps physically non-demanding, occupations. Selection of the controls from all other cancers should avoid these more obvious biases but does not, of course, guarantee that other unsuspected biases are not in operation. 
Death certificates for all cases and controls were extracted, and the occupational data were noted and reclassified by OPCS staff. It has been shown that such reclassification can greatly increase the ability of death certificate data to examine a particular area compared with use of the precoded data. ${ }^{18}$ Specific guidelines were produced for the inclusion of occupation descriptions in the respective categories which should have reduced, if not eliminated, any possibility of bias in the reclassification through knowledge of case or control status.

The occupation recorded on England and Wales death certificates is the last full-time occupation followed by the deceased (even if retired at time of death). It would clearly be preferable to have an occupation history but the effect of any occupational mobility is most likely to be a diffusion of the measured association between an occupation and mortality from this cause. Relative risks were calculated with $95 \%$ confidence intervals.

\section{Results}

Table 1 presents the results for selected occupations. Occupations with 15 or more cases are included plus one or two whose results may throw light on

Table 1 Cases and relative risks for testicular cancer for selected occupations: England and Wales 1971-80

\begin{tabular}{|c|c|c|c|}
\hline Occupation & $\begin{array}{l}\text { Number } \\
\text { of cases }\end{array}$ & $\begin{array}{l}\text { Relative } \\
\text { risk }\end{array}$ & $\begin{array}{l}95 \% \text { confidence } \\
\text { interval }\end{array}$ \\
\hline Fitters, millwrights, etc & 71 & 0.97 & $0.50-1.89$ \\
\hline Welders & 15 & 0.83 & $0.30-2 \cdot 33$ \\
\hline Steelworkers & 28 & $0 \cdot 68$ & $0.40-1 \cdot 14$ \\
\hline \multicolumn{4}{|l|}{ Foundry, furnace workers, boiler } \\
\hline operator, etc & 8 & 0.57 & $0.20-1.29$ \\
\hline Engineering nec & 217 & 0.88 & $0.72-1.08$ \\
\hline Painters and paint manufacturers & 37 & 0.92 & $0.47-1.82$ \\
\hline Printers & 25 & 1.48 & $0.73-2.98$ \\
\hline Food manufacture and preparation & 38 & $1 \cdot 82$ & $1 \cdot 04-3 \cdot 19$ \\
\hline All agricultural workers & 62 & 1.42 & $0.94-2 \cdot 14$ \\
\hline Farmers, farm managers & 44 & 1.85 & $1 \cdot 10-3 \cdot 11$ \\
\hline Farm workers & 18 & 0.90 & $0.25-3.23$ \\
\hline Butchers, slaughtermen & 15 & 0.83 & $0 \cdot 30-2 \cdot 33$ \\
\hline Electricians, electrical engineers, etc & 71 & 0.90 & $0.62-1.30$ \\
\hline Telecommunications engineers & 25 & 0.93 & $0 \cdot 31-2 \cdot 76$ \\
\hline Masons, bricklayers & 31 & $1 \cdot 15$ & $0 \cdot 58-2 \cdot 30$ \\
\hline Woodworkers, carpenters & 58 & 0.88 & $0.58-1.32$ \\
\hline Building workers, nec & 34 & 0.69 & $0 \cdot 43-1 \cdot 10$ \\
\hline Miners & 28 & 0.85 & $0.45-1.59$ \\
\hline Draughtsmen & 26 & 2.62 & $1 \cdot 23-5 \cdot 55$ \\
\hline Road vehicle drivers & 124 & 0.95 & $0.70-1.29$ \\
\hline Clerks & 82 & 0.95 & $0.70-1.29$ \\
\hline \multicolumn{4}{|l|}{ Retail and wholesale distribution } \\
\hline (excluding butchers) & 42 & $1 \cdot 08$ & $0.56-2.08$ \\
\hline Labourers nec & 91 & 0.71 & $0.54-0.94$ \\
\hline All professional workers & 132 & 1.44 & $1.09-1.90$ \\
\hline Accountants & 29 & $1 \cdot 26$ & $0.65-2.44$ \\
\hline Teachers, lecturers & 49 & $1 \cdot 14$ & $0.70-1.88$ \\
\hline Managers and company directors & 76 & 0.90 & $0.63-1.29$ \\
\hline Armed forces & 53 & $1 \cdot 21$ & $0.77-1.90$ \\
\hline Police & 20 & $1 \cdot 18$ & $0 \cdot 45-3 \cdot 12$ \\
\hline Merchant seamen & 16 & 0.84 & $0.31-2.99$ \\
\hline Firemen & 6 & 6.01 & $0.59-61.43$ \\
\hline
\end{tabular}

nec $=$ not elsewhere classified. previously hypothesised associations. The table reinforces the evidence of previous studies of raised risks for professional workers and lower risks for manual workers (engineering workers, labourers). Significant excess risks are noted for three occupations which do not immediately fit this pattern, however-food manufacture and preparation workers $(1.82)$, farmers $(1.85)$, and draughtsmen (2.62). The classification of food manufacture and preparation workers excludes retail and wholesale distribution, butchers, farmers, and all managers. Although it is a diverse group of workers, the raised risk is maintained across its major components (table 2) but, because of small numbers, none of the risks is statistically significant.

The excess risk for farmers (R/R 1.85) and the contrasting lack of excess risk for farm workers $(R / R$ 0.90 ) have been noted in a preliminary report ${ }^{19}$ of this study following an earlier reported association with agricultural employment. ${ }^{9}$

The excess risk for draughtsmen (R/R $2 \cdot 26$ on 26 deaths) is apparently previously unreported.

\section{Discussion}

This study has used data from mortality rather than incidence of testicular cancer because of the relative completeness and accuracy of the occupation data collected at death as opposed to cancer registration during the 1970s in England and Wales. ${ }^{20}$ Five year survival from registrations of this cancer in the period 1971-75 was between 65 and $70 \%,{ }^{21}$ and the possibility of bias due to differing relative survival must be considered. However, cancer registration data $^{22}$ for 1971-80 shows similar overall patterns to that suggested by this study with raised proportional registration ratios for professional workers and reduced ratios for unskilled workers. It seems unlikely, therefore, that any differences in survival between occupations would be sufficient to seriously bias the results of this mortality study.

The results of this study tend to confirm the conclusion that occupation by itself has a minor role at most in the aetiology of testicular cancer. ${ }^{1}$ The association with social class is confirmed with raised risks for professional workers and lower risks for manual workers, but clearly class here is acting as a

Table 2 Relative risk for food manufacture and preparation workers

\begin{tabular}{lcl}
\hline Occupation & Number of cases & Relative risk \\
\hline Chefs/cooks, etc & 13 & 1.63 \\
Bakers/flour mill workers, etc & 10 & 1.67 \\
Other food manufacture & 9 & $2 \cdot 25$ \\
Other food preparation & 6 & $2 \cdot 00$ \\
\hline
\end{tabular}


vague marker for other environmental, genetic, and/or behavioural factors. However, since occupation can influence both behaviour and environment, variations in mortality between occupations may be usefully studied.

A sedentary life style has been suggested as a risk factor for testicular cancer. ${ }^{1}$ The excess mortality for professional workers, and particularly for draughtsmen, may support this view, but the lack of any excess for road vehicle drivers and clerks does not concur. An alternative hypothesis of car driving ${ }^{1}$ as a contributory factor is also not supported. Several of the occupation groups in table 1 may be exposed to considerable heat in the course of their occupation, notably foundry and furnace workers, firemen, welders, and steelworkers. Out of these, only firemen show a relative risk greater than one, but none of the risks is statistically significant. The hypothesis of heat as a contributory factor in testicular cancer ${ }^{12}$ is therefore not supported by this study, but since the degree and consistency of heat exposure experienced by these occupations is unknown, this negative finding is not conclusive. The only identifiable occupation which might have some consistent experience of trauma ${ }^{11}$ would be professional sportsmen-our study produced two such cases and one control.

Mills and Newell have noted several studies which suggest farming and agriculture to be associated with an increased risk of testicular cancer, ${ }^{16}$ but other studies have failed to find this association..$^{23} 24$ In the present study an overall non-significant excess for all agricultural workers is clearly divisible into a significant excess for farmers and farm managers $(R / R 1.98)$ and a slight deficit for other farm workers (R/R 0.90).

Despite an increasing concentration of farm units in Britain, most farms in the country are still relatively small: it is estimated that in 1981 nearly half the farms would not fully occupy one person full-time. ${ }^{25}$ The number of large 'agribusiness' farms is still relatively small ${ }^{25}$ so most farmers are working farmers and might be expected to experience exposures to any occupational hazards of agriculture relatively similar to those of other farming workers.

The ability of death certificate occupation descriptions consistently to separate these two occupations may be questioned, but even so no ready explanation for this difference is available. Mills et al speculate on the role of an infectious agent in the aetiology of cancer of the testis, hypothesising that farm children may be exposed to a greater range of zoonotic viruses or may be more vulnerable to common childhood infections in later childhood through relative preschool isolation. ${ }^{9}$ Neither of these hypotheses, however, seems to account for the present study evidence of an excess mortality for farmers but not for farm workers, and the answer may be more in the social and behavioural differences between farmers and farm workers.

A possible association between testicular cancer and employment in food manufacture and preparation has been suggested by this study and is not readily amenable to explanations of selection of susceptible individuals into these occupations or common behavioural or environmental factors. The apparent consistency of the excess across cooks, bakers, and mill workers and other food manufacturing and preparation workers is of little help in reaching an explanation and requires further investigation. Further studies of the aetiology of testicular cancer will need to investigate a wide range of environmental and behavioural factors.

\section{References}

${ }^{1}$ Davies JM. Testicular cancer in England and Wales: some epidemiological aspects. Lancet 1981; i: 928-32.

${ }^{2}$ Schottenfeld D, Warshauer ME, Sherlock S, Zauber AG, Leder A, Payne R. The epidemiology of testicular cancer in young adults. Am J Epidemiol 1980; 112: 232-46.

${ }^{3}$ Lee JAH, Hitosugi M, Petersen GR. Rise in mortality from tumours of the testis in Japan, 1947-1970. J Nat Cancer Inst 1973; 51: 1485-90.

${ }^{4}$ Clemmesen J. A doubling of morbidity from testis carcinoma in Copenhagen, 1943-1962. Acta Path Microbia Scand 1968; 72: 348-9.

${ }^{5}$ Grummet RF, MacMahon B. Trends in mortality from neoplasms of the testis. Cancer 1958; 11: 790-7.

${ }^{6}$ Petersen GR, Lee JAH. Secular trend of malignant tumours of the testis in white men. J Nat Cancer Inst 1972; 49: 339-54.

${ }^{7}$ Editorial. Early testicular cancer. Lancet 1980; ii: 1175.

${ }^{8}$ Morrison AS. Crypotorchidism, hernia and cancer of the testis. J Nat Cancer Inst 1976; 56: 731-3.

${ }^{9}$ Mills PK, Newell GR, Johnson DE. Testicular cancer associated with employment in agriculture and oil and natural gas extraction. Lancet 1984; i: 207-11.

${ }^{10}$ Chilvers C, Pike MC, Forman D, Fogelman $K$, Wadsworth MEJ. Apparent doubling of frequency of undescended testis in England and Wales 1962-81. Lancet 1984; ii: 330-2.

${ }^{11}$ Collins AN. Trauma and malignant testis. Lancet 1935; 56: 139.

${ }^{12}$ Lin RS, Kessler LL. Epidemiologic findings in testicular cancer. (Abstract). Am J Epidemiol 1979; 110: 357.

${ }^{13}$ Graham S, Gibson R, West D, Swanson M, Burnet W, Dayal H. Epidemiology of cancer of the testis in upstate New York. J Nat Cancer Inst 1977; 58: 1255-61.

${ }^{14}$ Ross BK, McCurtis JW, Henderson BE, et al. Descriptive epidemiology of testicular and prostatic cancer in Los Angeles. BrJ Cancer 1979; 39: 284-92.

${ }^{15}$ Milham S. Neoplasia in the wood and pulp industry. Ann NY Acad Sci 1976; 271: 294-300.

${ }^{16}$ Mills PK, Newell GR. Testicular cancer risk in agricultural occupations. J Occup Med 1984; 26: 798-9.

${ }^{17}$ OPCS. Mortality statistics-cause (annual) series DH2. London: HMSO. 
${ }^{18}$ McDowall ME. Leukaemia mortality in electrical workers in England and Wales. Lancet 1983; i: 246.

${ }^{19}$ McDowall M, Balarajan $R$. Testicular cancer and employment in agriculture. Lancet 1984 ; i: 510.

${ }^{20}$ OPCS. Report of Advisory Committee on Cancer Registration 1980. MB1 No: 6. London: HMSO, 1981.

${ }^{21}$ OPCS. Cancer Statistics: Survival 1971-75 Registrations. MB1 No: 9. London: HMSO, 1982.
${ }^{22}$ OPCS. Cancer Statistics: Registration (annual) Series MB1. London: HMSO.

${ }^{23}$ Jensen OM, Olsen JH, Osteilmid A. Testis cancer risk among farmers in Denmark. Lancet 1984; i: 794.

${ }^{24}$ Brown LM, Pottern LM. Testicular cancer and farming. Lancet 1984; i: 1356.

${ }^{25}$ Phillips D, Williams A. Rural Britain. Oxford: Basil Blackwell, 1984. 